\title{
Unmet need in family planning at the Cape Coast Teaching Hospital of Ghana
}

\author{
Diallo Abdoul Azize ${ }^{1 *}$, Ekanem Evans², Agyare-Gyan Frederick ${ }^{3}$
}

\author{
${ }^{1}$ Department of Obstetrics and Gynecology, School of Medical Sciences, University of Cape Coast, Ghana \\ ${ }^{2}$ University Health Services, University of Cape Coast, Ghana \\ ${ }^{3}$ Department of Obstetrics and Gynecology, 37 Military Hospital, Accra Ghana
}

Received: 18 April 2019

Accepted: 30 May 2019

*Correspondence:

Dr. Diallo Abdoul Azize,

E-mail: diallo.azize@uccsms.edu.gh

Copyright: () the author(s), publisher and licensee Medip Academy. This is an open-access article distributed under the terms of the Creative Commons Attribution Non-Commercial License, which permits unrestricted non-commercial use, distribution, and reproduction in any medium, provided the original work is properly cited.

\begin{abstract}
Background: Knowing the prevalence of unintended pregnancy, unmet need in family planning and the associated factors in cape coast, is important for ensuring that all women have access to the most effective methods of family planning in order to reduce the occurrence of unintended pregnancies. This study aims to determine the prevalence of unintended pregnancies, unmet need in family planning and the associated factors among women attending antenatal clinics at the Cape Coast Teaching Hospital, Republic of Ghana.

Methods: A prospective cross-sectional study with descriptive and analytical components was carried out from $20^{\text {th }}$ April 2015 to $20^{\text {th }}$ June 2015 to simultaneously measure the prevalence of unmet need for family planning and related factors. All clients reporting for ANC at the Cape Coast Teaching Hospital during the study period were recruited into the study.

Results: A total of 324 clients were recruited. The mean age was $29.98 \pm 5.86$ years, $85.80 \%$ were married, $46.58 \%$ had tertiary education and $79.94 \%$ had a source of income. Up to $54.94 \%$ of the clients had not planned their index pregnancy. Among subjects who had not planned their index pregnancies, $74.71 \%$ had not used a family planning method. There is a significant association between age, educational level, the presence of a source of income, marital status and the occurrence of unplanned pregnancy.

Conclusions: There were high prevalence of unplanned pregnancy and unmet need for family planning. There is a significant association between age, educational level, the presence of a source of income, marital status and the occurrence of unplanned pregnancy.
\end{abstract}

Keywords: Antenatal, Cape Coast, Family planning, Family planning method, Unplanned pregnancy, Unmet need for family planning

\section{INTRODUCTION}

The World Health Organization (WHO) defines women with unmet needs in family planning as those who are fertile and sexually active but are not using any method of contraception, and report of not wanting any more children or wanting to delay the next child. ${ }^{1}$ Family planning is a key intervention in reducing maternal, neonatal and childhood mortality. ${ }^{2}$ Indeed, meeting women's unmet needs for modern contraceptives would result in $27 \%$ reduction in maternal deaths per year by preventing unintended pregnancies. ${ }^{3}$

The concept of unmet need in family planning highlights the gap between women's reproductive intentions and their contraceptive behavior. It was stated that achieving 
SDG target 3.1, namely: Ensuring access for all to sexual and reproductive health care services by 2030 , can be interpreted as $0 \%$ of unmet need in family planning. ${ }^{3}$

In West Africa, the subjective need for contraception remains unchanged; about $46 \%$ of married or cohabiting women reported a desire to stop and/or postpone childbearing for at least two years. ${ }^{4}$

In Ghana, the PMA survey conducted by Kwame Nkrumah University of Science and Technology estimated at $37.2 \%$ the prevalence of unmet need in family planning. ${ }^{5}$

However data on the prevalence of unintended pregnancy and unmet need in family planning in Cape Coast is not readily available and in literature rarely has unintended pregnancy been examined among pregnant women.

We conducted this study to add knowledge on the prevalence of unintended pregnancy, unmet need in family planning and the associated factors at the Cape Coast Teaching Hospital (Ghana).

\section{METHODS}

The study was carried out at the Directorate of Obstetrics and Gynecology, specifically at the Antenatal Unit of the Cape Coast Teaching Hospital (CCTH).

It was a cross-sectional study with prospective data collection over a period of two months - from April 20 $0^{\text {th }}$, 2015 to June $19^{\text {th }}, 2015$. The population of study was composed of clients coming for antenatal consultation at the Cape Coast Teaching Hospital during the study period.

The size of the sample (324 respondents) was calculated from the proportion's formula applicable in crosssectional studies: $\left(\mathrm{n}=\mathrm{z}^{2} \mathrm{pq} / \mathrm{me}^{2}\right)$.

p: Proportion of $37 \%$ women with an unmet need for family planning was considered on the basis of previous studies. $^{5}$

Subjects were selected using systematic sampling. A structured questionnaire was used as a tool for data collection. Client interview was the survey technique used.

\section{Inclusion criteria}

- All pregnant women, who reported for antenatal services at the Cape Coast Teaching Hospital during the study period and have consented to the survey.

\section{Exclusion criteria}

- The pregnant women who reported with complications of pregnancy.

\section{Statistical analysis}

Data entry and data analysis were done using Epi Info version 7. Data were presented as mean and standard deviation. Chi-square and Fisher Exact tests were used to compare between qualitative variables. P-value considered statistically significant when $\mathrm{P}<0.05$. The dependent variable was the planning of the index pregnancy. The unmet need for planning was determined by the lack of use of a modern family planning method.

We obtained the approval of the authorities of the Cape Coast Teaching Hospital prior to the survey. Anonymity and confidentiality of the data was observed. Informed consent of the clients was obtained prior to their inclusion in the study.

\section{RESULTS}

Socio-demographic characteristics the mean age of the clients was $29.98 \pm 5.86$ years, with extremes of 15 and 45 years. The Table 1 shows the age distribution, the level of education, the marital status and the profession of the respondents, where the majority of them $(95.68 \%)$ were older than 20 years and $85.80 \%$ were married. Almost half $(46.58 \%)$ of them had tertiary education. More than three-quarters $(79.94 \%)$ had a source of income either as employees or self-employed.

Table 1: Socio-demographic characteristics of the respondents.

\begin{tabular}{|lll|}
\hline Characteristics & Numbers & $\%$ \\
\hline Age (years) & 14 & 4.32 \\
\hline$<20$ & 42 & 12.96 \\
\hline $20-25$ & 92 & 28.39 \\
\hline $26-30$ & 102 & 31.48 \\
\hline $30-35$ & 74 & 22.83 \\
\hline$\geq 35$ & & \\
\hline Level of education & 35 & 10.80 \\
\hline Never attended school & 51 & 15.74 \\
\hline Basisc education & 88 & 27.16 \\
\hline High school & 150 & 46.29 \\
\hline Tertiary & & \\
\hline Marital status & 278 & 85.80 \\
\hline Married & 36 & 11.11 \\
\hline Single & 10 & 3.08 \\
\hline Divorced/separated/widow & & \\
\hline Profession & 134 & 41.35 \\
\hline Employed with income & 128 \\
\hline Self employed & 62 & 39.50 \\
\hline $\begin{array}{l}\text { Student/Housewives/ } \\
\text { unemployed }\end{array}$ & & 19.13 \\
\hline
\end{tabular}

\section{Obstetrical characteristics}

More than half of the respondents, $66.67 \%(n=216)$ had given birth before, with parity ranging between 1 and 7 . 
The mean parity was 1.27 with a standard deviation of 1.39. Among the clients who had delivered before, $77.22 \% \quad(\mathrm{n}=156)$ had spontaneous vaginal delivery. The current inter pregnancy interval was less than 12 months in 32 cases $(14.18 \%)$ and less than 2 years in 91 cases $(28.2 \%)$.

\section{Unplanned pregnancy}

More than half of the clients, 54.94\% ( $\mathrm{n}=178)$, had not planned their pregnancies. Among the 178 subjects who had not planned their pregnancies, only $25.28 \%(n=45)$ used intermittently a family planning method. Figure 1 shows the methods of contraception used, the most used method was the traditional methods (sometime in combination with the male condom) in 27 of case $(59.00 \%)$ of cases, oral contraceptive was used by 14 respondent $(31.11 \%)$ and emergency contraceptive by 8 respondents $(8.8 \%)$.

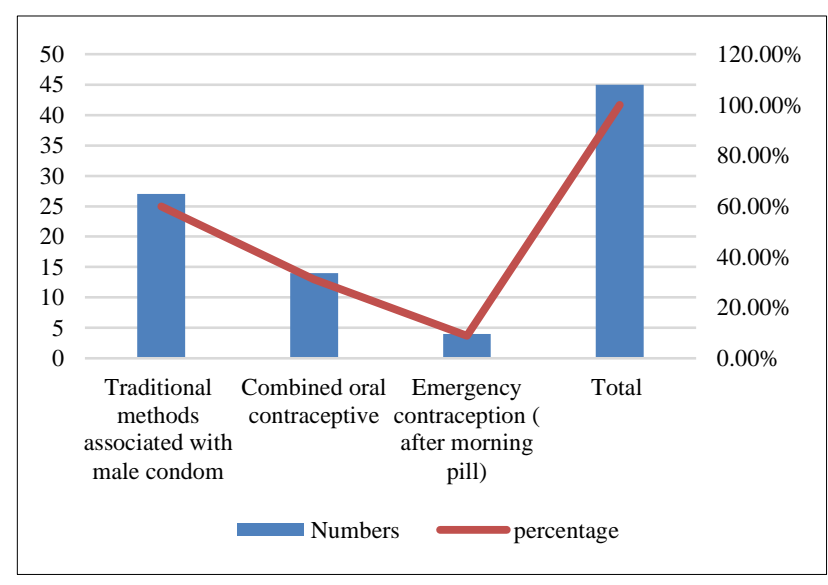

Figure 1: Methods of family planning used by the respondents who attempted to avoid pregnancy $(n=45)$.

\section{Unmet need for family planning}

Among the clients who had not planned their current pregnancy, 133 of them $(74.71 \%)$ had not used a family planning method. The reasons for non-usage of FP were dominated by fear about side effects including delay in fertility (39.09\%), previous negative personal experiences $(22.55 \%)$ and lack of family planning counseling $(15.05 \%)$.

\section{Factors associated with unplanned pregnancies}

We conduct a statistical analysis on the characteristics of clients and their association with unplanned pregnancies, Table 2, summarizes the association between planning of pregnancy and client's characteristics with the respective P-values. There was a significant association between age, educational level, the presence of a source of income, marital status and the occurrence of unplanned pregnancy with P-values of $0,01,0.0003,0.0004$ and
0.0001 respectively. However women's parity was not significantly associated (P-value of 0.9).

Table 2: Association between planning of pregnancy and client's characteristics.

\begin{tabular}{|c|c|c|c|}
\hline Characteristics & $\begin{array}{l}\text { Planned } \\
\text { pregnancy }\end{array}$ & Total & $\begin{array}{l}\text { P- } \\
\text { values }\end{array}$ \\
\hline \multicolumn{4}{|l|}{ Age } \\
\hline$<35$ years & $116(52.7 \%)$ & 220 & \multirow{2}{*}{0.01} \\
\hline$\geq 35$ years & $34(45.9 \%)$ & 74 & \\
\hline \multicolumn{4}{|c|}{ Level of education } \\
\hline $\begin{array}{l}\text { Secondary and } \\
\text { tertiary }\end{array}$ & $94(39.4 \%)$ & 238 & \multirow[t]{2}{*}{0.0003} \\
\hline Primary & $29(33.7 \%)$ & 86 & \\
\hline \multicolumn{4}{|c|}{ Existence of a source of income } \\
\hline Yes & $136(51.9 \%)$ & 262 & \multirow{2}{*}{0.0004} \\
\hline No & $24(38.7 \%)$ & 62 & \\
\hline \multicolumn{4}{|l|}{ Marital status } \\
\hline Married & $138(49.6 \%)$ & 278 & \multirow{2}{*}{0.0001} \\
\hline Singles & $9(19.5 \%)$ & 46 & \\
\hline \multicolumn{4}{|l|}{ Parity } \\
\hline Multiparous & $98(45.3 \%)$ & 216 & \multirow{2}{*}{0.09} \\
\hline Nulliparous & $48(44.4 \%)$ & 108 & \\
\hline
\end{tabular}

\section{DISCUSSION}

More than half of the clients $(54.94 \%)$ had not planned the pregnancy they were carrying. They wanted to delay the current pregnancy or to stop childbirth. Our results are higher than those of the national level in Ghana, which was $30 \%$ and $42 \%$ respectively for married women and sexually active single women. ${ }^{6}$ They are also higher than those reported by Ikamari in Kenya. ${ }^{7}$ Hailemariam in Ethiopia and Mbacké Faye in Senegal, which were respectively $24 \%, 37.4 \%$ and $14.3 \%$. $^{8,9}$

The prevalence of unplanned pregnancies recorded in Sub Saharan Africa of $39 \%$ was also lower than our result. ${ }^{9}$ However our results are close to those of a study conducted in 18 hospitals in Latin America who found a prevalence of $49.8 \%$ among 5155 mothers interviewed in the postpartum period. ${ }^{10}$

Our relative higher prevalence of unplanned pregnancy could be explained by the fact that, we have interviewed the respondent while they are pregnant, while most of the studies were population based with non-pregnant respondents and most unwanted or unplanned pregnancies become wanted after birth. Our finding could be the true picture of unplanned pregnancies. The lack of use of contraceptive method $(74.71 \%)$ and the practice of traditional methods $(27 / 45=59.00 \%)$ known for the higher rate of failure among those who tried a form of contraception, explains the high prevalence of unplanned pregnancies in our population.

The level of education had an effect on pregnancy planning $(p=0.0003)$. This association has also been 
noted by studies in sub-Saharan Africa. ${ }^{9,11-13}$ This reveals the need to educate women to reduce the unmet need for family planning. However, studies in Nairobi and in Latin America have not shown an association between education and pregnancy planning. ${ }^{7,10}$ Having a source of income was significantly associated with planning of pregnancy $(p=0.0004)$, the studies by Faye in Senegal and Ikmari in Kenya made the same observation.,8 Marital status was significantly associated with planning of pregnancy $(\mathrm{p}=0.001)$. These results are consistent with those of the literature. ${ }^{9}$ The clients' parity was not significantly associated with planning of pregnancy $(p=0.09)$. The opposite has been observed by studies in Latin America and Kenya., ${ }^{7,9}$ Indeed, the study in Kenya found that parities 1-2 and those of at least 3 were respectively more likely to have an unplanned pregnancy than nulliparous. ${ }^{7}$ Out of the respondent who had not planned their pregnancy, the majority, $74.71 \%$ had not used a family planning method. Our prevalence of unmet need for family planning was comparable to those in Côte d'Ivoire, Senegal and Benin, which were $88.00 \%, 82.70 \%$ and $80.30 \%$ respectively. ${ }^{14}$

\section{CONCLUSION}

There was an unmet need in family planning in Cape Coast even among the educated women which has resulted in a high proportion of unintended pregnancies. Those unintended pregnancies were linked to a lower use of modern methods of family planning. The reasons given for not using FP were dominated by fear about side effects including delay in fertility. There is a significant association between age, educational level, the presence of a source of income, marital status and the occurrence of unintended pregnancy. The results of our study suggest the need to have targeted and customized contents for family planning counseling.

\section{ACKNOWLEDGMENTS}

Authors would like to thank Dr Eric Ngedu (currently CEO of the Cape Coast Teaching Hospital) and the midwives at the antenatal clinic of the Cape Coast teaching Hospital.

Funding: No funding sources

Conflict of interest: None declared

Ethical approval: The study was approved by the Institutional Ethics Committee

\section{REFERENCES}

1. WHO: Unmet need for family planning. 2015. Available at: http://www.who.int /reproductive health/topics/family_planning/unmet_need. Accessed on $4^{\text {th }}$ January, 2015.

2. Postpartum Family Planning Programming Strategy. World Health Organization publication. Geneva, Switzerland. 2013. Available at: https://www.who.int/reproductivehealth/publications/ family_planning/ppfp_strategies/en/. Accessed on $3^{\text {rd }}$ January 2015.

3. Singh S, Jacqueline D, Lori S. Adding It Up: The Costs and Benefits of Investing in Family Planning and Maternal and Newborn Health. New York: Guttmacher Institute and UNFPA, 2009. Available at: https://www.guttmacher.org/report/adding-itmeeting-contraceptive-needs-of-adolescents. Accessed on $3^{\text {rd }}$ January 2015.

4. Cleland JG, Ndugwa RP, Zulu EM. Family planning in sub-Saharan Africa: progress or stagnation? Bull World Health Organ. 2011;89(2):137-43.

5. PMA, Key family planning indicators 2014. Available at: http://www.pma2020.org / programcountries / Ghana. Accessed on $3^{\text {rd }}$ January 2015.

6. Ghana Statistical Service, Ghana Health Service, The DHS Program, ICF International. Ghana Demographic and Health Survey. 2014. Accra Ghana. April 2015.

7. Lawrence I, Chimaraoke I, Rhoune O. Prevalence and determinants of unintended pregnancy among women in Nairobi, Kenya. BMC. 2013;13:69.

8. Hailemariam A, Haddis F. Factor's affecting unmet need for family planning in Southern Nations, Nationalities and Peoples Region, Ethiopia. Ethiop J Health Sci. 2011;21(2):77-89.

9. Mbacké FS, Ilene SS, Fotso C, Corroon M, Djimadoum K. Unintended pregnancy: magnitude and correlates in six urban sites in Senegal. Biomed Central Reproduct Health. 2013;10:59.

10. Enrique CG, Joaquin EP, Jorge SL. Unintended pregnancies in women at 18 South American Hospitals: Human Reproduction. 1998;13(7):1991-5.

11. Magadi MA. Unplanned childbearing in Kenya: the socio-demographic correlates and the extent of repeatability among women. Social Sci Med. 2003;56(1):167-78.

12. Rhoda KW, Haruna L, Susan MK. Determinants of family planning service and contraceptive use among postpartum women in rural Uganda. Int J Pub Health. 2015;60(8):987-97.

13. Lance A, Mc Guire JJ, Dalton V. Predictors of patients use of highly effective postpartum contraception. Contraception. 2010;82(2): 191.

14. Ross JA, Winfrey WL. Contraceptive use, intention to use and unmet needs during the extended postpartum period. Int Family Planning Perspect. 2001;27:20-2.

Cite this article as: Azize DA, Evans E, Frederick AG. Unmet need in family planning at the Cape Coast Teaching Hospital of Ghana. Int J Reprod Contracept Obstet Gynecol 2019;8:2582-5. 